\title{
Social Acknowledgment of Violent Experiences and Its Role in PTSD and Appetitive Aggression Among High-Risk Males in South Africa
}

Clinical Psychological Science 2017, Vol. 5(1) 166-173 (C) The Author(s) 2016 Reprints and permissions: sagepub.com/journalsPermissions.nav DOI: $10.1177 / 2167702616658634$ journals.sagepub.com/home/cpx @SAGE

\author{
Jessica Sommer ${ }^{1}$, Martina Hinsberger' ${ }^{1}$, Roland Weierstall ${ }^{1}$, \\ Leon Holtzhausen ${ }^{2}$, Debra Kaminer ${ }^{2}$, Soraya Seedat ${ }^{3}$, Andreas \\ Maercker $^{4}$, Solomon Madikane ${ }^{5}$, and Thomas Elbert ${ }^{1}$ \\ ${ }^{1}$ University of Konstanz, ${ }^{2}$ University of Cape Town, ${ }^{3}$ Stellenbosch University, ${ }^{4}$ University of Zurich, \\ and ${ }^{5}$ REALISTIC, Gugulethu, South Africa
}

\begin{abstract}
Violence exposure poses a risk for posttraumatic stress disorder (PTSD) and appetitive aggression. Does acknowledgment of violent experiences by one's social environment also affect these adverse consequences of violence? We investigated relations between number of traumatic event types, number of violent offenses, PTSD symptoms, appetitive aggression, and social acknowledgment. A total of 290 participants were recruited through a Cape Town rehabilitation center for offenders. Using path analysis, we demonstrate higher societal disapproval to be associated with more intense PTSD symptoms and greater appetitive aggression. However, past experiences of recognition were also related to more intense PTSD symptoms. Violence exposure was positively associated with PTSD symptoms and appetitive aggression, and a higher number of violent offenses was related to greater appetitive aggression. Results indicate that besides violence exposure, social acknowledgment may play a significant role in the severity of PTSD and appetitive aggression. Intervention programs should not neglect targeting social structures.
\end{abstract}

\section{Keywords}

violence exposure, social acknowledgment, PTSD, appetitive aggression, South Africa

Received 10/31/15; Revision accepted 6/15/16

Violence exposure has been highlighted as one major risk factor for the development of posttraumatic stress disorder (PTSD; Köbach, Schaal, \& Elbert, 2015; Neugebauer et al., 2009): PTSD symptoms increase with cumulative exposure to different traumatic events, known as the building block effect (Neuner et al., 2004; Wilker et al., 2015). Furthermore, traumatic experiences are also related to a lowered threshold for aggression (Barbarin, Richter, \& deWet, 2001; Benhorin \& McMahon, 2008); they can cause anger and hyperarousal, which may be also expressed by a "fight" reaction in line with the new clinical conceptualizations of PTSD in the Diagnostic and Statistical Manual of Mental Disorders (5th ed.; American Psychiatric Association, 2013).

Yet being exposed to violence may also lead to habituation, involving a more normative and less aversive experience of aggression and thus a lower threshold for self-perpetrated atrocities (Guerra, Huesmann, \& Spindler, 2003). Baumeister and Campbell (1999) postulate that with increased violent offending, a pleasure of harming others emerges. This thrill of hunting down someone, known as appetitive aggression (Elbert, Moran, \& Schauer, in press; Elbert, Weierstall, \& Schauer, 2010), may arise when the environment trains the individual to behave cruelly and when this fosters survival strategies. Appetitive aggression may therefore reduce the risk of developing PTSD (Hecker et al., 2013; Weierstall, Schaal, Schalinski, Dusingizemungu, \& Elbert, 2011) and may thus promote an adaptation to conditions in which

Corresponding Author:

Jessica Sommer, Department of Psychology, University of Konstanz, PO Box 23/25, 78457 Konstanz, Germany

E-mail: jessica.sommer@uni-konstanz.de 
violent threats are frequently encountered. However, considering the long-term consequences for both community and individual, appetitive aggression may still be understood as an adverse effect because this shift from victimization to perpetration poses a risk for further aggression.

Given the findings, a question of interest is why some individuals who grow up in violent environments develop PTSD or appetitive aggression whereas others do not. Studies indicate that social support may serve as a resiliency factor in PTSD (L. A. King, King, Fairbank, Keane, \& Adams, 1998). Furthermore, with regard to PTSD symptom severity, Maercker and Müller (2004) investigated the role of social acknowledgment of an individual's violent experiences, that is, a part of social support that not only embraces the instrumental and emotional support offered to an individual by his or her close environment, but also refers to the societal context, in which the affected individual may feel excluded due to his or her violent experiences. Social acknowledgment comprises three subscales, of which the positively poled subscale Recognition, that is, the perceived appreciation as someone in a difficult state of suffering, was related to fewer PTSD symptoms (Maercker \& Müller, 2004; Maercker, Povilonyte, Lianova, \& Pöhlmann, 2009), whereas its negatively poled subscales Family Disapproval and General Disapproval, that is, the invalidation or rejection of the victim's traumatic experiences by the family or social environment, were related to more PTSD symptoms (Littleton, 2015; Schumm, Koucky, \& Bartel, 2014).

Regarding appetitive aggression, social acknowledgment may also be protective: Serious delinquency is often found in young men who feel rejected by their social environment (Miller-Johnson, Coie, Maumary-Gremaud, Lochman, \& Terry, 1999) and consequently join gangs, thereby forming subcultures within their community. This creates another downward spiral: High levels of aggression may provoke further rejection (Bolger \& Patterson, 2001), whereas feeling excluded may foster violence (Twenge, Baumeister, Tice, \& Stucke, 2001). Thus far, the impact of social acknowledgment of past experiences in a sample with offender attributes has not been rigorously studied.

South Africa reports one of the highest homicide rates, with $46.0 \%$ of injury deaths caused through interpersonal violence-almost 5 times the global average (Seedat, Van Niekerk, Jewkes, Suffla, \& Ratele, 2009). Youth from poor communities are at particularly high risk for traumatization (Shields, Nadasen, \& Pierce, 2008) and absorption into gang structures (Ward \& Bakhuis, 2010). We investigated in a South African high-risk population with victim and offender attributes (a) whether family and general disapproval were positively related to PTSD and appetitive aggression, and recognition, in turn, negatively; (b) whether trauma exposure was positively related to both PTSD symptoms as well as appetitive aggression; and (c) whether the number of violent offenses was positively related to appetitive aggression.

\section{Method}

\section{Participants}

In 2013-2014, 290 Black Xhosa-speaking South African males from low-income neighborhoods around Cape Town were recruited through a community-based organization attempting to rehabilitate offenders and youth at risk. Recruitment focused on those currently attending the program (20\%) and those previously having taken part or at risk for perpetrating or becoming victims of crime $(80 \%)$. There were no significant differences between the two groups concerning all included variables $(p>.24$, Mann-Whitney $U$ test) except for recognition $(p=.02)$, which was significantly higher in those participating in the program at the time of the interview $(M=1.50, S D=0.61)$ compared with those who were not ( $M=1.30, S D=0.65)$. Ages ranged from 14 to 40 years ( $M=21.96, S D=4.53)$. The educational background was rather low with $81 \%$ of the participants having had less than 12 years of education.

\section{Materials}

Number of traumatic event types. Exposure to potentially traumatic events was assessed using an adapted 36-item list from the Children's Exposure to Violence Checklist (CEVC; Amaya-Jackson, 1998). The CEVC has demonstrated excellent psychometric properties (Martin, Revington, \& Seedat, 2013) and has proven its validity in South African offender populations (Weierstall et al., 2013). Items assess threats to one's physical integrity, direct victimization, and witnessing of traumatic events, which were rated dichotomously: 0 if participants had not experienced the event, 1 if they had. Traumatic event types were summed with possible scores ranging from 0 to 36 points. The reliability of the adapted version of the CEVC in our sample was high (Kuder-Richardson $\alpha=$.97). Traumatic events ranged from 5 to 32 different events $(M=18.71, S D=5.11)$.

PTSD symptom severity. PTSD symptoms during the past 2 weeks were assessed with the PTSD Symptom Scale-Interview (PSS-I; Foa \& Tolin, 2000). For each of the 17 items, possible ratings ranged from 0 (not at all) to 3 (very much), indicating the extent to which the trauma led to each of the $\mathrm{B}$ (reexperiencing), $\mathrm{C}$ (numbing/avoidance), and D (hyperarousal) PTSD symptoms of the DSM-IV-TR (4th ed., text rev.; American Psychiatric 
Association, 2000). Studies have established this measure's validity in South African offender populations (Weierstall et al., 2013). We summed the score of all items. Cronbach's alpha in this sample was .88. PTSD symptoms ranged from 0 to 39 points $(M=8.49, S D=$ 9.07).

Appetitive aggression. We assessed attraction to violence using the Appetitive Aggression Scale (AAS; Weierstall \& Elbert, 2011), which has been validated in South African offender populations (Weierstall et al., 2013). It consists of 15 statements (e.g., "While fighting, does the desire to hunt or kill take control of you?") with ratings ranging from 0 (I totally disagree) to 4 (I totally agree). For the analysis, the sum score was calculated. Cronbach's alpha in this sample was .86. AAS scores ranged from 0 to 60 points $(M=15.42, S D=13.08)$.

Number of violent offenses. To measure perpetrated violence, we used a list of 21 different offense types (e.g., physical/sexual assault) from the AAS, which has been successfully administered in South African offenders (Weierstall et al., 2013). We summed the number of violent offense types for the analysis. Kuder-Richardson alpha in this sample was .87 . Offense types ranged from 1 to 21 different offenses $(M=11.65, S D=4.35)$.

Social acknowledgment. The Social Acknowledgment Questionnaire, which has demonstrated good psychometric properties (Maercker \& Müller, 2004), assesses individuals' perceptions of recognition or disapproval from society and their family after traumatic experiences. The 16 items are scored from 0 (not at all) to 3 (completely) and divided into three subscales: one positively poled (Recognition; e.g., "Important figures of public life in my place of residence expressed their sympathy for me after the violent incidents"), two negatively (General Disapproval; e.g., "Somehow I am no longer a normal member of society since the violent incidents"; Family Disapproval; e.g., "My family feels uncomfortable talking about my experiences"). The questionnaire was adapted to fit the participants' profiles as victims and perpetrators of violence. The item "My boss showed full understanding for any absence from work" was adapted (possible answer: not applicable) to the participants' living conditions, where having a superior is rare due to high unemployment (Kingdon \& Knight, 2004). To adjust for this circumstance the recognition score, which included the critical item, was calculated either by 5 or 6 , based on whether the question was rated or not. As $85.9 \%$ of the participants answered not applicable, the item was excluded from the Cronbach's alpha analysis (recognition, $\alpha=.56$; general disapproval, $\alpha=.71$; family disapproval, $\alpha=.51$ ). Recognition scores ranged from 0 to $3(M=1.33, S D=0.65)$, general disapproval scores from 0 to $15(M=7.15, S D=3.78)$, and family disapproval scores from 0 to $15(M=6.21, S D=3.36)$.

\section{Procedure}

Diagnostic interviews were led by four German mental health experts and three local counselors, all of whom had received intensive training in the concepts of trauma, appetitive aggression, and clinical diagnosis through the use of structured interviews. Bilingual first-language isiXhosa-speaking interpreters, specifically trained for translations in clinical settings, assisted with the interviews. Questionnaires were translated into isiXhosa by bilingual interpreters and back-translated into English.

The study protocol was approved by the Ethical Review Boards of the University of Konstanz, University of Cape Town, and the Health Research Ethics Committee of Stellenbosch University. Participants received financial compensation for participation in the interviews and gave informed consent (consent for minors was given by parents or caretakers).

\section{Data analyses}

Path analyses were performed with Amos 22 for SPSS. To test the hypothesized relations, we included number of traumatic event types, number of violent offenses, general disapproval, family disapproval, and recognition as predictors and PTSD and appetitive aggression as outcomes. To increase the variation range in the investigated variables, the two subgroups were integrated into one model and group membership was included as a control variable. Of 290 participants, 36 had missing data on any of the variables; these values were estimated using maximum likelihood estimation, providing more accurate estimates of population parameters than other methodological approaches (e.g., case deletion; Enders, 2006).

\section{Results}

According to fit criteria (Hu \& Bentler, 1999), our hypothesized model fit the data well: $\chi^{2}(2, N=290)=3.72$, $p=.156$, comparative fit index $(\mathrm{CFI})=.995$, root mean square error of approximation (RMSEA) $=.055,90 \%$ $\mathrm{CI}=[.000, .140]$. However, the hypothesized links from family disapproval to PTSD and appetitive aggression and from recognition to appetitive aggression did not achieve significance. Furthermore, no significant paths between the control variable and the endogenous variables existed. All nonsignificant links were excluded in a stepwise manner and a revised model obtained (Fig. 1). 


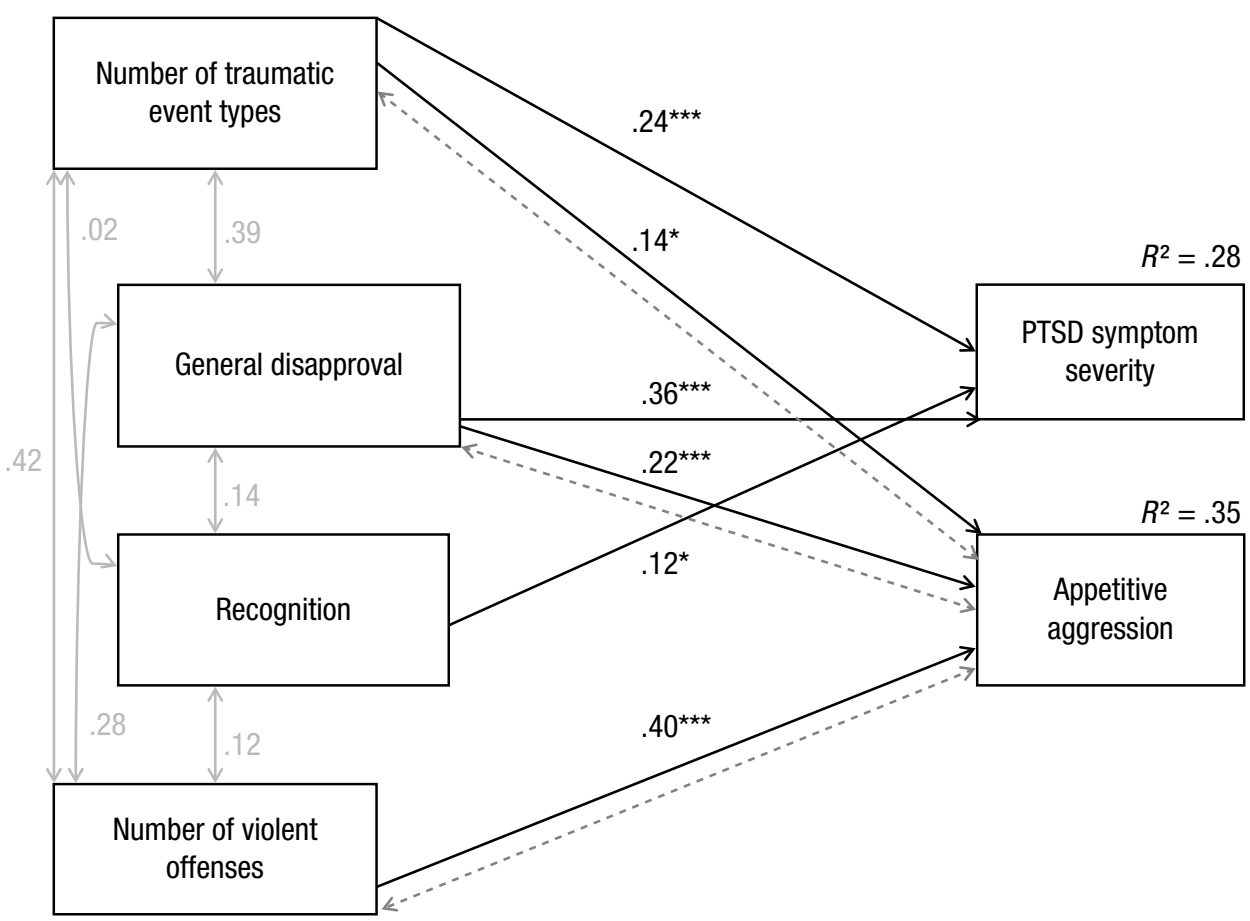

Fig. 1. Path model of relations among number of traumatic event types, number of violent offenses, general disapproval, recognition, PTSD symptoms, and appetitive aggression. Paths with one arrowhead indicate directed associations. Double-headed arrows represent covariances. Paths connected through dotted arrows indicate possible reciprocal relations. Standardized regression weights are shown. ${ }^{*} p<.05$. ***k $p<.01$. ***** $p<.001$.

The revised model accounted for $28 \%$ of the variance in PTSD and for $35 \%$ in appetitive aggression. The model's fit statistics were good: $\chi^{2}(3, N=290)=4.52, p=.211$, $\mathrm{CFI}=.995$, RMSEA $=.042,90 \% \mathrm{CI}=[.000, .115]$. General disapproval was positively related to PTSD and appetitive aggression. Recognition was positively related to PTSD but not significantly related to appetitive aggression. Participants reporting more traumatic event types demonstrated higher PTSD and appetitive aggression scores. A higher number of violent offenses was also related to higher appetitive aggression.

PTSD symptoms (a) and appetitive aggression (b) related to the number of traumatic event types and general disapproval are shown in Figure 2. Participants with high trauma load but low general disapproval did not report severe PTSD symptoms and had mainly low appetitive aggression, whereas severe PTSD symptoms and extreme appetitive aggression occurred mainly when general disapproval was high alongside multiple traumatic event types.

\section{Discussion}

This study examined relations between number of traumatic event types, number of violent offenses, social acknowledgment (general disapproval, family disapproval, recognition), PTSD symptoms, and appetitive aggression in high-risk males from poor communities around Cape Town. Using path analyses, and in line with longitudinal findings (Wagner, Keller, Knaevelsrud, \& Maercker, 2011), we found a positive relation between general disapproval and PTSD. Perceiving a lack of sympathy may lead to more PTSD symptoms. A similar effect was observed for appetitive aggression: The stronger the feeling that one is no longer a normal community member, the greater seemed the propensity to engage in violence, which may be due to a hostile cognitive mindset, activated by social rejection (DeWall, Twenge, Gitter, \& Baumeister, 2009). However, one could also argue that general disapproval on the part of society may have been related to rejection as a reaction to the offenses emerging from appetitive aggression. Because the cross-sectional design of our investigation does not allow for the determination of causality, further research is needed to clarify causality. Nevertheless, our results do suggest general disapproval to be an important factor in improving our understanding of what may promote PTSD and appetitive aggression.

In our study, only general disapproval—not family disapproval-was positively related to PTSD. This pattern 
a

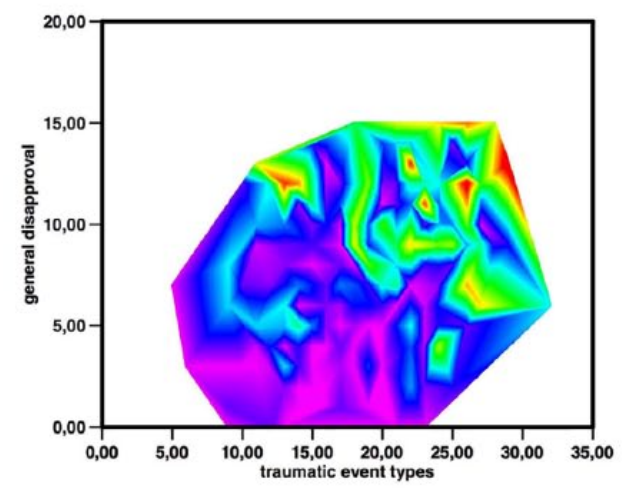

b

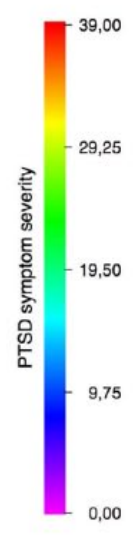

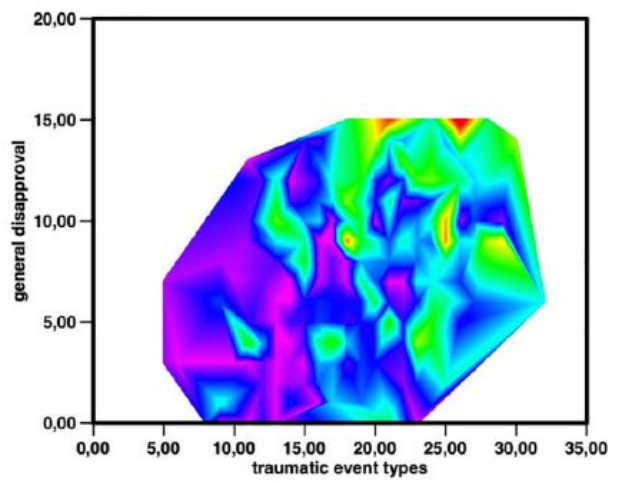

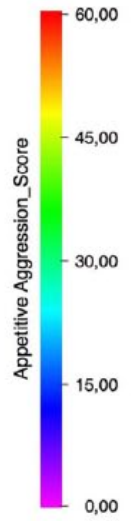

Fig. 2. Relationships among general disapproval, number of traumatic event types, and (a) PTSD symptoms and (b) appetitive aggression. With increasing general disapproval (ordinate), the severity of (a) PTSD symptoms and (b) appetitive aggression (color coding) increases along with different traumatic stressors (abscissa).

has been shown before (Schumm et al., 2014), but the reasons for these findings are not yet well understood. Ullman and Filipas (2001) suggested that different origins of acknowledgment may become more or less important according to an individual's cultural background, sex, or type of traumatic experience. Furthermore, family disapproval did not seem to play a significant role in appetitive aggression. In our sample, this may be explained by membership in a gang often being associated not only with a spatial but also an internal separation from one's family; extensive drug abuse and poor parental supervision have been found to be present in the family backgrounds of young men joining gangs (Eitle, Gunkel, \& Van Gundy, 2004). In the search for a surrogate family (Ruble \& Turner, 2000), they may not have been greatly exposed to their own families' reactions to their past violent experiences; or the evaluation of these experiences by the individual's family may no longer have been meaningful, whereas the individual's friend's reactions, within the broader social environment, may have had a greater impact on these youths.

Recognition from others-for example, from peers and social workers in offender reintegration programswas not significantly related to appetitive aggression, but was positively related to PTSD. Based on studies with victim populations, this was unanticipated. Yet flowing from the idea that PTSD and appetitive aggression share violence exposure as a common etiology, one explanation could be that PTSD symptoms elicit more social recognition than aggressive ones. It might, however, also be in line with findings of Weierstall, Schalinski, Crombach, Hecker, and Elbert (2012) and Hecker et al. (2013), suggesting that appetitive aggression may serve as an antidote to the development of PTSD under certain circumstances. When attending a reintegration program, former offenders are asked to process their past and are confronted with negative consequences of committing violence. Formerly positive attitudes toward aggression may thereby be transformed in a stressful examination of one's offenses and history. Because aggression is viewed as a coping mechanism for dealing with trauma in adverse environments (Spaccarelli, Coatsworth, \& Bowden, 1995), PTSD symptoms may increase as the positive "gangster" self-image is destroyed. This finding highlights the importance of providing trauma interventions when working with offenders.

Furthermore, we replicated the dose-response effect between the number of traumatic event types and PTSD symptoms (Neugebauer et al., 2009; Wilker et al., 2015). Moreover, cumulative exposure to traumatic stressors was related to higher appetitive aggression. PTSD symptoms such as hyperarousal and hostility can lead to reactive aggression (Hellmuth, Stappenbeck, Hoerster, \& Jakupcak, 2012), which may turn into appetitive aggression as the individual learns that acting aggressively in a cruel environment can entail the advantages of no longer being a victim; appetitive aggression therefore may represent a survival strategy (Crombach \& Elbert, 2014; Hecker et al., 2013). Although longitudinal studies have indicated causal relations between violence exposure and subsequent violence perpetration (Schwab-Stone et al., 1999), one can however also argue that the likelihood of violence exposure rises with the motivation to perpetrate violence, as offenses are often accompanied by traumatic events like being attacked by a rival gang (Scarpa \& Haden, 2006).

In addition, studies in war zones indicate that a higher number of violent offenses is related to higher levels of 
appetitive aggression (Köbach et al., 2015). This effect was also found in our sample; however, it is difficult to deduce whether appetitive aggression arises from violent acts or whether appetitive aggression leads to violent acts that in turn increase appetitive aggression even further. Most likely, the two factors interact in a cycle of violence (Elbert, Rockstroh, Kolassa, Schauer, \& Neuner, 2006).

In highly traumatized populations, affected individuals may not always get a chance to talk about their struggles, as traumatic experiences may be normative and therefore less acknowledged (Scarpa \& Haden, 2006). This may worsen posttrauma adjustment and promote appetitive aggression. The improvement of social acknowledgment after violent experiences should therefore be considered as an important target for interventions intending to lower PTSD rates (Maercker et al., 2009) and to reduce appetitive aggression.

Sharing narratives of perpetrators, who have often been victimized themselves before turning violent (Malik, Sorensen, \& Aneshensel, 1997), may be helpful to promote acknowledgment of the perpetrator's state of suffering in community-wide meetings, to open up dialogues that facilitate a better understanding of aggression (R. U. King \& Sakamoto, 2015), and to build positive support systems of classmates, teachers, and other members of the community, which may contribute to decreased rates of aggression (Benhorin \& McMahon, 2008).

Our study included only South African high-risk young males and the external validity of the findings remains to be demonstrated. Social desirability may have played a role when participants answered questions about their self-committed offenses, possibly leading to an increase in the error variance of the data. Furthermore, given the correlational nature of this cross-sectional study, conclusions about causal relations require additional evidence from longitudinal studies.

Despite the harmful effects of chronic community violence (i.e., increased risk of PTSD and appetitive aggression), important factors such as social acknowledgment of violent experiences that have not been addressed in similar studies on victims with offender attributes have been identified in this study. Improvements in the social environment may help youths to overcome adverse life circumstances and in turn contribute to breaking the vicious cycle of violence.

\section{Author Contributions}

All authors developed the study concept and contributed to its design. Data collection was performed by J. Sommer and M. Hinsberger. J. Sommer analyzed and interpreted the data and drafted the manuscript. T. Elbert and R. Weierstall provided supervision and critical revisions. All authors approved the manuscript's final version for submission.

\section{Acknowledgments}

We thank the participants, the REALISTIC staff, our local supporters, and Noah Lorenz and Veronika Wieshammer for making this study possible. Roland Weierstall is now at Clinical Psychology and Psychotherapy, Medical School Hamburg.

\section{Declaration of Conflicting Interests}

The authors declared that they had no conflicts of interest with respect to their authorship or the publication of this article.

\section{Funding}

This research was supported by the European Research Council (T.E., ERC-2012-AdG 323977 Memo TV). This research was also supported by the German National Academic Foundation (J.S.).

\section{References}

Amaya-Jackson, L. (1998). Child's Exposure to Violence Checklist. Durham, NC: Centre for Child and Family Health, Trauma Evaluation, Treatment and Research Program.

American Psychiatric Association. (2000). Diagnostic and statistical manual of mental disorders (4th ed., text rev.). Washington, DC: Author.

American Psychiatric Association. (2013). Diagnostic and statistical manual of mental disorders (5th ed.). Washington, DC: Author.

Barbarin, O. A., Richter, L., \& deWet, T. (2001). Exposure to violence, coping resources, and adjustment of South African children. American Journal of Orthopsychiatry, 7, 16-25. doi:10.1037//0002-9432.71.1.16

Baumeister, R. F., \& Campbell, W. K. (1999). The intrinsic appeal of evil: Sadism, sensational thrills, and threatened egotism. Personality and Social Psychology Review, 3, 210221. doi:10.1207/s15327957pspr0303_4

Benhorin, S., \& McMahon, S. D. (2008). Exposure to violence and aggression: Protective roles of social support among urban African American youth. Journal of Community Psychology, 36, 723-743. doi:10.1002/jcop.20252

Bolger, K. E., \& Patterson, C. J. (2001). Developmental pathways from child maltreatment to peer rejection. Child Development, 72, 549-568. doi:10.1111/1467-8624.00296

Crombach, A., \& Elbert, T. (2014). The benefits of aggressive traits: A study with current and former street children in Burundi. Child Abuse \& Neglect, 38, 1041-1050. doi:10.1016/j.chiabu.2013.12.003

DeWall, C. N., Twenge, J. M., Gitter, S. A., \& Baumeister, R. F. (2009). It's the thought that counts: The role of hostile cognition in shaping aggressive responses to social exclusion. Journal of Personality and Social Psychology, 96, 45-59. doi:10.1037/a0013196.

Eitle, D., Gunkel, S., \& Van Gundy, K. (2004). Cumulative exposure to stressful life events and male gang membership. Journal of Criminal Justice, 32, 95-111. doi:10.1016/j.jcrim jus.2003.12.001

Elbert, T., Moran, J., \& Schauer, M. (in press). Appetitive aggression. In B. J. Bushman (Ed.), Aggression and violence. New York, NY: Taylor \& Francis/Routledge. 
Elbert, T., Rockstroh, B., Kolassa, I., Schauer, M., \& Neuner, F. (2006). The influence of organized violence and terror on brain and mind- $\mathrm{A}$ co-constructive perspective. In $\mathrm{P}$. Baltes, P. Reuter-Lorenz, \& F. Roesler (Eds.), Lifespan development and the brain: The perspective of biocultural coconstructivism (pp. 326-363). Cambridge, England: Cambridge University Press. doi:10.1017/CBO9780511499722.017

Elbert, T., Weierstall, R., \& Schauer, M. (2010). Fascination violence: On mind and brain of man hunters. European Archives of Psychiatry and Clinical Neuroscience, 260, 100-105. doi:10.1007/s00406-010-0144-8

Enders, C. K. (2006). A primer on the use of modern missing-data methods in psychosomatic medicine research. Psychosomatic Medicine, 68, 427-736. doi:10.1097/01 .psy.0000221275.75056.d8

Foa, E. B., \& Tolin, D. F. (2000). Comparison of the PTSD Symptom Scale-interview version and the clinicianadministered PTSD Scale. Journal of Traumatic Stress, 13, 181-191. doi:10.1023/A:1007781909213

Guerra, N. G., Huesmann, L. R., \& Spindler, A. (2003). Community violence exposure, social cognition, and aggression among urban elementary school children. Child Development, 74, 1561-1576.

Hecker, T., Hermenau, K., Mädl, A., Hinkel, H., Schauer, M., \& Elbert, T. (2013). Aggression inoculates against PTSD symptom severity insights from armed groups in the eastern DR Congo. European Journal of Psychotraumatology, 4, 20070. doi:10.3402/ejpt.v4i0.20070

Hellmuth, J. C., Stappenbeck, C. A., Hoerster, K. D., \& Jakupcak, M. (2012). Modeling PTSD symptom clusters, alcohol misuse, anger, and depression as they relate to aggression and suicidality in returning U.S. veterans. Journal of Traumatic Stress, 25, 527-534. doi:10.1002/jts.21732

Hu, L., \& Bentler, P. M. (1999). Cutoff criteria for fit indexes in covariance structure analysis: Conventional criteria versus new alternatives. Structural Equation Modeling, 6, 1-55. doi:10.1080/10705519909540118

King, L. A., King, D. W., Fairbank, J. A., Keane, T. M., \& Adams, G. A. (1998). Resilience-recovery factors in posttraumatic stress disorder among female and male Vietnam veterans: Hardiness, postwar social support, and additional stressful life events. Journal of Personality and Social Psychology, 74, 420-434. doi:10.1037/0022-3514.74.2.420

King, R. U., \& Sakamoto, I. (2015). Disengaging from genocide harm-doing and healing together between perpetrators, bystanders, and victims in Rwanda. Peace and Conflict: Journal of Peace Psychology, 21, 378-394. doi:10.1037/ pac0000078

Kingdon, G. G., \& Knight, J. (2004). Race and the incidence of unemployment in South Africa. Review of Development Economics, 8, 198-222. doi:10.1111/j.14679361.2004.00228.x

Köbach, A., Schaal, S., \& Elbert, T. (2015). Combat high or traumatic stress: Violent offending is associated with appetitive aggression but not with symptoms of traumatic stress. Frontiers in Psychology, 5, 1518. doi:10.3389/ fpsyg.2014.01518
Littleton, H. L. (2015). The impact of social support and negative disclosure reactions on sexual assault victims: A cross-sectional and longitudinal investigation. Journal of Trauma $\varepsilon$ Dissociation, 11, 210-227. doi:10.1080/15299730903502946

Maercker, A., \& Müller, J. (2004). Social acknowledgment as a victim or survivor: A scale to measure a recovery factor of PTSD. Journal of Traumatic Stress, 17, 345-351. doi:10.1023/B:JOTS.0000038484.15488.3d

Maercker, A., Povilonyte, M., Lianova, R., \& Pöhlmann, K. (2009). Is acknowledgment of trauma a protective factor? The sample case of refugees from Chechnya. European Psychologist, 14, 249-254. doi:10.1027/1016-9040.14.3.249

Malik, S., Sorensen, S. B., \& Aneshensel, C. S. (1997). Community and dating violence among adolescents: Perpetration and victimization. Journal of Adolescent Health, 21, 291-302.

Martin, L., Revington, N., \& Seedat, S. (2013). The 39-item Child Exposure to Community Violence (CECV) Scale: Exploratory factor analysis and relationship to PTSD symptomatology in trauma-exposed children and adolescents. International Journal of Behavioral Medicine, 20, 599-608. doi:10.1007/s12529-012-9269-7

Miller-Johnson, S., Coie, J. D., Maumary-Gremaud, A., Lochman, J., \& Terry, R. (1999). Relationship between childhood peer rejection and aggression and adolescent delinquency severity and type among African American youth. Journal of Emotional and Behavioral Disorders, 7, 137-146. doi:10.1177/106342669900700302

Neugebauer, R., Fisher, P. W., Turner, J. B., Yamabe, S., Sarsfield, J. A., \& Stehling-Ariza, T. (2009). Posttraumatic stress reactions among Rwandan children and adolescents in the early aftermath of genocide. International Journal of Epidemiology, 38, 1033-1045. doi:10.1093/ije/dyn375

Neuner, F., Schauer, M., Karunakara, U., Klaschik, C., Robert, C., \& Elbert, T. (2004). Psychological trauma and evidence for enhanced vulnerability for PTSD through previous trauma in West Nile refugees. BMC Psychiatry, 4, 34. doi:10.1186/1471-244X-4-34

Ruble, N. M., \& Turner, W. L. (2000). A systematic analysis of the dynamics and organization of street gangs. American Journal of Family Therapy, 28, 117-132. doi:10.1080/019261800261707

Scarpa, A., \& Haden, S. C. (2006). Community violence victimization and aggressive behavior: The moderating effects of coping and social support. Aggressive Behavior, 32, 502 515. doi:10.1002/ab.20151

Schumm, J. A., Koucky, E. M., \& Bartel, A. (2014). Associations between perceived social reactions to trauma-related experiences with PTSD and depression among veterans seeking PTSD treatment. Journal of Traumatic Stress, 27, 50-57. doi: $10.1002 /$ jts. 21879

Schwab-Stone, M., Chen, C., Greenberger, E., Silver, D., Lichtman, J., \& Voyce, C. (1999). No safe haven II: The effects of violence exposure on urban youth. Journal of the American Academy of Child and Adolescent Psychiatry, 38, 359-367. doi:10.1097/00004583-199904000-00007

Seedat, M., Van Niekerk, A., Jewkes, R., Suffla, S., \& Ratele, K. (2009). Violence and injuries in South Africa: Prioritising 
an agenda for prevention. Lancet, 374, 1011-1022. doi:10.1016/S0140-6736(09)60948-X

Shields, N., Nadasen, K., \& Pierce, L. (2008). The effects of community violence on children in Cape Town, South Africa. Child Abuse \& Neglect, 32, 589-601. doi:10.1016/j .chiabu.2007.07.010

Spaccarelli, S., Coatsworth, J. D., \& Bowden, B. S. (1995). Exposure to serious family violence among incarcerated boys: Its association with violent offending and potential mediating variables. Violence and Victims, 10, 163-182.

Twenge, J. M., Baumeister, R. F., Tice, D. M., \& Stucke, T. S. (2001). If you can't join them, beat them: Effects of social exclusion on aggressive behavior. Journal of Personality and Social Psychology, 81, 1058-1069. doi:10.1037/00223514.81.6.1058

Ullman, S. E., \& Filipas, H. H. (2001). Predictors of PTSD symptom severity and social reactions in sexual assault victims. Journal of Traumatic Stress, 14, 369-389. doi:10.1023/A:1011125220522

Wagner, B., Keller, V., Knaevelsrud, C., \& Maercker, A. (2011). Social acknowledgment as a predictor of post-traumatic stress and complicated grief after witnessing assisted suicide. International Journal of Social Psychiatry, 58, 381385. doi: $10.1177 / 0020764011400791$

Ward, C. L., \& Bakhuis, K. (2010). Intervening in children's involvement in gangs: Views of Cape Town's young people. Children \& Society, 24, 50-62. doi:10.1111/j.10990860.2009.00195.x

Weierstall, R., \& Elbert, T. (2011). The Appetitive Aggression Scale-Development of an instrument for the assessment of human's attraction to violence. European Journal of Psychotraumatology, 2, 8430. doi:10.3402/ejpt.v2i0.8430

Weierstall, R., Hinsberger, M., Kaminer, D., Holtzhausen, L., Madikane, S., \& Elbert, T. (2013). Appetitive aggression and adaptation to a violent environment among youth offenders. Peace and Conflict: Journal of Peace Psychology, 19, 138-149. doi:10.1037/a0032489

Weierstall, R., Schaal, S., Schalinski, I., Dusingizemungu, J.-P., \& Elbert, T. (2011). The thrill of being violent as an antidote to posttraumatic stress disorder in Rwandese genocide perpetrators. European Journal of Psychotraumatology, 2, 6345. doi:10.3402/ejpt.v2i0.6345

Weierstall, R., Schalinski, I., Crombach, A., Hecker, T., \& Elbert, T. (2012). When combat prevents PTSD symptoms-Results from a survey with former child soldiers in Northern Uganda. BMC Psychiatry, 12, 41. doi:10.1186/1471-244X-12-41

Wilker, S., Pfeiffer, A., Kolassa, S., Koslowski, D., Elbert, T., \& Kolassa, I. T. (2015). How to quantify exposure to traumatic stressors? Reliability and validity of measures for cumulative trauma exposure in a post-conflict population. European Journal of Psychotraumatology, 6, 28306. doi:10.3402/ejpt .$v 6.28306$ 